\title{
Simón Rodríguez: una biografía enredada en las pedagogías
}

\author{
Wainsztok, Carla \\ Universidad de Buenos Aires, Argentina \\ carlalatina2@ hotmail.com
}

Cita sugerida: Wainsztok, C.(2018). Simón Rodríguez: una biografía enredada en las pedagogías. Archivos de Ciencias de la Educación, 12 (13), e041. https://doi.org/10.24215/23468866e041

Recibido: 03 Febrero 2018 - Aceptado: 24 Abril 2018 - Publicado: 29 de junio de 2018

(i)(5) Esta obra está bajo licencia Creative Commons Atribución-NoComercial-CompartirIgual 4.0 Internacional hitp://creativecommons.org/licenses/by-nc-sa/4.0/deed.es_AR 


\title{
Simón Rodríguez: una biografía enredada en las pedagogías
}

\author{
Carla Wainsztok \\ Universidad de Buenos Aires, Argentina \\ carlalatina2@hotmail.com
}

Simón Rodríguez: an entangled biography in pedagogies

\section{RESUMEN:}

Este artículo se presenta como una biografía pedagógica de Simón Rodríguez, pionero de la educación popular en América Latina en el siglo XVIII. ¿Puede ser Simón Rodríguez nuestro contemporáneo? Esta pregunta atraviesa el texto buscando interpelar concepciones y prácticas vigentes. Rodríguez compartió con Simón Bolívar el ideal de construcción de la Patria Grande, pensando una escuela para todos desde el Sur. Trama de concepciones sobre ciudadanía, trabajo, igualdad y educación que contrastan con las lógicas neoliberales y coloniales. ¿Importar ideas o que las ideas importen?, remite a inventamos o erramos, frase remarcada del pensamiento de Rodríguez, y a la necesidad de construir gramáticas pedagógicas que permitan nombrar-nos, ejercer la pregunta desde las experiencias vitales, habilitar una geonarrativa frente a la embestida neoliberal actual.

Palabras ClaVe: Gramáticas pedagógicas latinoamericanas, Educación popular, Epistemologías del Sur, Colonialidad.

\section{Abstract:}

This article is presented as a SimónRodríguez 's pedagogical biography, pioneer of popular education in Latin America in the 18th century. Can Simon Rodriguez be our contemporary? This question crosses the text seeking to interpellate current conceptions and practices. Rodriguez shared with Simón Bolivar the dream of building the Great Homeland in Latin America, thinking of a school from the South for everyone. Weft made of conceptions about citizenship, work, equality and education that contrast with neoliberal and colonial logics. The question "to import ideas or make ideas matter?", refers to the famous phrase "we invent or we err", that marked Rodriguez's thought, and to the need to build pedagogical grammars that allow us to name ourselves, to practice the question from life experiences, enable a geonarrative facing the current neoliberal onslaught.

KEYWORDS: Latin America pedagogical grammars, Popular education, Epistemologies from the South, Coloniality.

\section{UNA BIOGRAFÍA PEDAGÓGICA}

Escribir la biografía de Simón Rodríguez en las pedagogías, enredar las biografías en las historias de Nuestra América Latina. Los tiempos de las biografías, las temporalidades de las pedagogías. Las historias no son solo cronologías, están henchidas de anhelos, de pasiones, de conflictos. Las historias no son lineales. Pasados, presentes y futuros se funden y confunden por un instante en una pregunta: ¿Podría Simón Rodríguez ser nuestro contemporáneo?

Escribir las pedagogías de los deseos. Escribir en las pedagogías, los deseos. Deseos de igualdades, de libertades. Pedagogías deseantes, biografías deseosas. Los deseos y los comienzos. Los comienzos de los deseos.

Así comienza un libro sobre Rodríguez: "Toda obra de reflexión, como toda obra de arte es trabajo del deseo, y proviene de ese punto incandescente que anima desde lo hondo del sujeto lo que en él se debate en cada acto de su vida" (Rozitchner, 2012, p. 21).

Así empieza la "Etica Nicomáquea" de Aristóteles: “Todo arte y toda investigación científica, así como toda acción y toda elección, parecen tender a algún bien; por eso se ha definido con razón, el bien como aquello a lo que todas las cosas aspiran" (Aristóteles, 2002, p. 13). 
Dos comienzos, entre deseos y el bien. El trabajo del deseo, el deseo trabajoso de cada elección. Dos comienzos y una pregunta: ¿Por qué los derechos se conquistan y los deseos se piden?

Los hombres no están en Sociedad para decirse que tienen necesidades -ni para aconsejarse que busquen como remediarlasni para exhortarse a tener paciencia; sino para consultarse sobre los medios de satisfacer sus deseos, porque no satisfacerlos es padecer (Rodríguez; 2015, p. 92).

¿Se puede construir pedagogías sin deseos? ¿Se puede construir sin deseos?

Los derechos sociales también son deseos. El derecho al conocimiento es el deseo de saberes y de reconocimiento. El derecho al conocimiento es el derecho a conocer nuestros derechos. Escribir en el presente, en este presente sobre derechos y deseos. Insistir en los derechos y los deseos. Los derechos y los deseos se pueden desplegar o precarizar.

¿Qué formas tenían los derechos y los deseos en el siglo XVIII? Un maestro soñó con deseos de libertades e igualdades. En un mundo colonial, un maestro aspiró a la construcción de otros mundos con otros mundos. Simón Rodríguez nació el 28 de octubre de 1769, en Caracas, y murió el 28 de febrero de 1854, en Paita (Perú). Decidió ser maestro y enseñar en Europa y en América Latina.

Fue el maestro de Bolívar entre 1792 y 1797. En sus textos pueden leerse las ideas y los deseos de igualdad, emancipación y libertad que acompañaron el proyecto bolivariano que él también alumbró. Compartieron mundos, visiones y cosmovisiones como puede leerse en una carta que el discípulo envió a su maestro:

¡Oh mi maestro! ¡oh mi Amigo! ¡Oh mi Robinson! V. en Colombia, V en Bogotá y nada me ha dicho, nada me ha escrito. Sin duda es V. el hombre más extraordinario del mundo! (...) V. formó mi corazón para la libertad, para la justicia, para lo grande, para lo hermoso (Rodríguez, 2015, p. 181).

Entonces decimos proyecto bolivariano-rodrigueano. Leyendo cuidadosamente, maestro y discípulo compartían una idea enorme:

Es una idea grandiosa pretender formar de todo el Nuevo Mundo una sola nación con un solo vínculo que ligue sus partes entre sí y con el todo. Ya que tiene un origen, una lengua, unas costumbres y una religión debería, por consiguiente, tener un solo gobierno que confederase los diferentes estados que hayan de formarse, mas no es posible, porque climas remotos, situaciones diversas, intereses opuestos, caracteres desemejantes dividen a la América. iQué bello sería que el istmo de Panamá fuera para nosotros lo que el Corintio para los griegos! (Bolívar, 1990, p. 81).

Para Rodríguez construir la Patria Grande significaba formar ciudadanos, pueblos y maestros. Toda una construcción pedagógica. Rodríguez piensa, escribe y sueña con una escuela para todos desde el Sur.

(...) llegado a este caso ¿quién hará que las voluntades se pongan de acuerdo? ¿Será aquel sentimiento del deber, que coarta las facultades del poder?... Este sentimiento nace del conocimiento que cada uno tiene de sus verdaderos intereses; y para adquirir este conocimiento debe haber Escuelas en las Repúblicas... y Escuela para todos, porque todos son ciudadanos (Rodríguez, 1988 T. 1, p. 283).

La idea de ciudadanía no está asociada a la de propiedad privada, como sí lo estaba en Europa, donde ser ciudadano era sinónimo de ser propietario, varón y heterosexual. Incluso en la obra de Rousseau pueden encontrarse distinciones entre la educación de Emilio y la de Sofía.

Rodríguez lee, cita a Rousseau y lee al mismo tiempo desde el Sur. Leer a otros pensadores al mismo tiempo que leer nuestros territorios para poder construir una epistemología del Sur. La "epistemología del sur" es el nombre de un texto actual de un pensador portugués que busca nuevas maneras de recrear conocimientos y reconocimientos.

(...) la búsqueda de conocimiento y de criterios de validez del conocimiento que otorguen visibilidad y credibilidad a las prácticas cognitivas de las clases, los pueblos y de los grupos sociales que han sido históricamente victimizados, explotados y oprimidos, por el colonialismo y el capitalismo globales. El Sur es, pues, usado aquí como metáfora del sufrimiento humano sistemáticamente causado por el colonialismo y el capitalismo (De Sousa Santos, 2009, p. 12). 
Si las geografías son los dibujos de la tierra; las geopolíticas, construir políticas desde el territorio; si Rodolfo Kusch imaginó geoculturas, nos gusta nombrar a este leer, pensar y problematizar desde el Sur como geonarrativas. Las pedagogías están siendo gramáticas y geonarrativas. Narrarnos desde nuestras experiencias vitales y pedagógicas. Experiencias y existencias. Las experiencias y las existencias como historias para pensar las reexistencias. Para inventar resistencias.

Narrar y pensar. Pensar para no repetir. Pensar es problematizar. Los tiempos del pensar. El pensar de los tiempos. Viejos y nuevos tiempos. Las temporalidades que se conjuran y conjugan. Pensar es lo contrario de imitar o copiar: "El estado actual de la América pide serias reflexiones:... Aprovechen los Americanos de la Libertad de Imprenta que se han dado para consultarse sobre el importante negocio de su libertad" (Rodríguez, 2015, p. 21).

El pensar y la libertad, el pensar y las libertades. Pedagogías y libertades, no pedagogías para las libertades. Las pedagogías como agite de las libertades y estas como agite de los pensamientos. Rodríguez nos propone pensar desde los territorios pedagógicos e imaginar libertades en una sociedad colonial: "En la América del Sur las Repúblicas estaban establecidas pero, aún no fundadas" (2015, p. 21).

Desde esta premisa, fundar y refundar repúblicas conlleva la importancia de enseñar y aprender a vivir y a convivir como ciudadanas/os y pueblos. Si la versión liberal sólo menciona la formación ciudadana, el maestro de Bolívar plantea la necesidad y el deseo de formar ciudadanas/os y pueblos. "Nada importa tanto como el tener Pueblo: formarlo debe ser la única ocupación de los que se apersonan por la causa social” (Rodríguez; 1988 TI, p. 283).

Fundar y formar como lo contrario de prohibir e impedir conocer(nos). Las pedagogías no son impedimentos ni imposiciones, no son concebidas por el ideario rodrigueano como prohibiciones ni prescripciones, sino como pedagogías humanizantes, vitales, humanas y humeantes como el pan.

No puede negarse que es inhumanidad, el privar a un hombre de los conocimientos que necesita para entenderse con sus semejantes, puesto que, sin ellos, su existencia es precaria i su vida...miserable. La Instrucción es, para el espíritu, lo que, para el cuerpo, el Pan (Rodríguez; 2015, p. 91).

Robinson-Rodríguez sabe que las políticas y las pedagogías pueden construir sueños o pesadillas. Por eso le preocupan las infancias: "Esto es los cholitos y las cholitas que ruedan en las calles" (Rodríguez; 1988 TII, p.517). Por ello afirma:

¡Entre tantos hombres de juicio.... de talento.... de algún caudal.... como cuenta la América!....jentre tantos bienintencionados!... entre tantos... ipatriotas!... (tómese esta palabra en su sentido recto) no hay uno que ponga los ojos en los niños pobres. No obstante, en éstos está

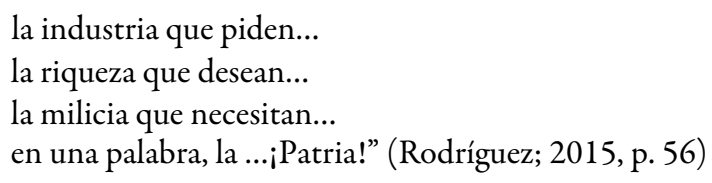

Resonancias textuales y amorosas que aparecen en otros tiempos, que llevamos en nuestros oídos: los únicos privilegiados son los niños, la patria es el otro. Y también le preocupan los adultos:

(...) en vida de Bolívar pude ser lo que hubiera querido, sin salir de la esfera de mis aptitudes. Lo único que le pedí fue que se me entregaran, de los Cholos los más pobres, los más despreciados, para irme con ellos a los desiertos del Alto Perú (Rodríguez, Tomo I, 1988, p. 255).

Las y los desharrapados de las tierras “(...) dénseme los muchachos pobres, o dénseme lo que los hacendados declaran libres al nacer, los que no pueden enseñar, los que abandonan por rudos, a los que ya están grandes, a los que no pueden mantener" (Rodríguez, Tomo I, 1988, p. 313).

Niñas/os, jóvenes, adultas/os, no hay singularidades "ineducables". Con las/os expulsadas/os quiere echar su suerte andar. Por ello, para que la igualdad y la emancipación no sean una simple declaración o 
declamación, Rodríguez decide combinar “economía social, con una educación popular” (1988 TI., p. 299). En el Colegio de Latacunga se ha de enseñar: "Castellano y Quichua, Física, Química, Historia Natural y se establecerán dos fábricas una de loza y otra de vidrio, se crearía una maestranza de albañilería, carpintería y herrería" (Rodríguez, 1988 T.II, pp. 34-35).

Educación popular y trabajo que no es empleo ni emprendurismo. El trabajo como creación, como producción. Un llamado a crear y producir las existencias y sus modos de producción. Se abre así camino a la potencia, la poiesis y la posibilidad que ofrece la educación.

¿Cómo "crear" potencias y posibilidades bajo un vendaval neoliberal? La pregunta no es: ¿cómo hacer pedagogías en estos días? La pregunta es: ¿cómo no hacer pedagogías? El aula como un espacio de resistencia ante las élites de ayer y de hoy, que son los mismos nombres. Los apellidos de las élites se repiten hoy como ayer en toda Nuestra América Latina. A veces estos nombres y apellidos se despliegan en el estado, construyendo estados de mal-estar como en nuestro país, en otros países se repliegan pero allí están tratando de destruir estados plurinacionales.

En Bogotá comienza Rodríguez su experiencia pedagógica original, a la que va a llamar Casa de Industria Pública. La escuela como una casa donde se produce y se crean pedagogías y trabajos. Los trabajos de las pedagogías. Tareas pedagógicas que vinculan trabajos y mundos. Las manos que hacen y aman. Luego desarrolla su tarea en Chuquisaca, y sus ideas se despliegan en un texto que se titula Consejos de amigo, allí se dirige a Rafael Quevedo, rector del Colegio de San Vicente. Para que la igualdad y la emancipación no sean una simple declaración o declamación, Rodríguez decide combinar “economía social, con una educación popular” (1988 TI., p. 299), le sugiere construir cátedras de lenguas, física, química e historia. También le advierte que su proyecto no va a ser bien recibido por los "Doctores de antaño" (p. 35), ya que allí se enseña a "hablar la Lengua de los Bárbaros y haciendo platos, botellas, tapias, silletas y clavos” (p. 35). Pero, el maestro de Bolívar sabe también que:

[los]doctores americanos no advierten que deben su ciencia a los indios y a los negros: porque si los señores doctores hubieran tenido que arar, sembrar, recoger, cargar y confeccionar lo que han comido, vestido y jugado durante su vida inútil... no sabrían tanto... estarían en los campos y serían tan brutos como sus esclavos (p. 359).

Hay un dato más:

Los clérigos y los abogados viejos se apoderaron de Sucre, le hicieron echar a la calle más de dos mil niños, que yo tenía matriculado y cerca de mil recogidos. Pretendieron ponerme bajo las órdenes (de los Prefectos), a enseñar a leer y a gritar la Biblia, según Lancaster (...) Aplicaron el dinero a fundar Casas de Misericordia, Recovas, Institutos de Caligrafía para el Bello Sexo, etc., como hacen las naciones cultas: porque el fondo era de Beneficiencia; i que Beneficiencia quiere decir dar caldo claro a los pobres, i aconsejarles que tengan paciencia; poner debajo de techo a los regatones, para que las patatas no se mojen; encargar, matronas virtuosas, las niñas que tengan dinero, para que aprendan el pudor por principios etc. como hacen las naciones cultas (...) consiguieron que Sucre me desaire en público, porque abogaba por los Frailes, empleados: en fin, dieron con la Empresa por tierra (Rodríguez; Tomo II, 1988, p. 533).

El proyecto político-pedagógico de Rodríguez es la educación popular: educación que implica la existencia de un "estado educador" (Roig, 1976, p. 179). Frente a las escuelas de la colonia, propone la creación de escuelas para la Patria, de escuelas para las "Nuevas Repúblicas" (Rodríguez, Tomo I, 1988, p. 333), ya que es necesario que el gobierno establezca "una Escuela en que se enseñe lógica, Idioma y Cálculo” (p. 401). La tarea es pedagógica y política. Por lo tanto, el maestro de niños "debe ser sabio, ilustrado, filósofo i comunicativo, porque su oficio es formar hombres para la sociedad” (p. 541).

Parafraseando a Gramsci, pensador italiano (1891-1937), el problema de la educación es el principal problema de clase. Esta afirmación nos remite a una vieja y clásica pregunta: ¿Cómo generar contrahegemonía desde el discurso hegemónico? Y, para presentarlo como un problema pedagógico: ¿Dónde se formarán los nuevos docentes? ¿En qué tipo de instituciones pedagógicas? Afirma Rodríguez: "Forme un NUEVO plan de enseñanza y establézcalo con Maestros NUEVOS” (Tomo I, 1988, p. 254). Sin embargo, en otro de sus 
textos, sostiene: "Establezcase una NUEVA enseñanza, con Maestros NUEVOS; sin excluir, de los actuales a los que quieran sujetarse a un NUEVO Reglamento" (Tomo II, 1988, p.19).

Para Rodríguez, la "enseñanza se plantea no desde la paz sino desde la guerra de la Independencia. Pero de una independencia que está todavía por ser alcanzada y cuyo camino debe ser enseñado para que permanezca abierto" (Rozitchner, 2012, p.33). Nos remite de este modo a las distintas formas de colonialismos y neocolonialismos, y nos invita a pensar sobre los modos de conquistar igualdades, emancipaciones e independencias. ¿Escribir y abrir escuelas en un contexto de guerras? ¿Desear pedagogías en un contexto neoliberal/neocolonial? "El estado actual de la América pide serias reflexiones... Aprovechen los americanos de la Libertad de Imprenta” (Rodríguez, 1988 T.I, p. 261).

Nos podemos preguntar si las libertades aún por conquistar piden reflexiones o las reflexiones habilitan las libertades. Esto nos conduce a plantear a las conquistas de las libertades en tiempos difíciles.

La mano y la pluma como generadores de una gramática y de una política. Rodríguez nos convoca a escribir para pensar y pensar para escribir. Pensar para no imitar: "o Inventamos o Erramos" (1988 T.I, p. 343). Pensar-escribir como la contracara de imitar: "El hombre que piensa, procede en todo según su conciencia, y el que no piensa...imita” (1988 T.I, p. 284).

Pensar e inventar para no padecer, para crear eros allí donde tánatos intenta destruir todo. Rodríguez nos convoca a entender a la capacidad de pensar como generadora de ideas vivas, por eso imitar es repetir, copiar, una de las formas de encasillarse. La imitación es parte de la importación de ideas. Nos surgen las preguntas: ¿Importar ideas? ¿O que las ideas propias importen?, y afirma nuestro maestro: “ $¡ T$ Traer Ideas Coloniales a las Colonias! ... es un Extraño antojo. ¿Estamos tratando de quemar las que tenemos?” (Rodríguez, 1988 T.I, p. 345). Así se refiere a importar mercancías, ideas y hasta maestras y maestros:

Con el mayor de los descaros se habla ya, en nuestras tertulias, de la llegada de una Colonia de Maestros, con un cargamento de Catecismitos sacados de la Enciclopedia por una sociedad de jentes de letras en Francias, i por hombres aprendidos en Inglaterra. El fin es, no solo desterrar el Castellano, sino quitar a los niños hasta las ganas de preguntar por qué piden pan" (Rodríguez, 1988 T.I, p. 348).

En tiempos de miseria(s) se vuelve necesario hacerse preguntas y volverse pregunta. Y no es cualquier pregunta, es la pregunta por el hombre, por las deshumanizaciones. Una pedagogía de la pregunta, que devela y nos desvela por los modos y los sentidos de vivir en sociedades americanas.

\section{LA METÁFORA LANCASTER}

Las políticas y las pedagogías. Los tiempos de las gestiones, las temporalidades pedagógicas. Las gestiones políticas que no son sugestiones mediáticas. Ayer y hoy. Las políticas (socio)educativas y las gramáticas pedagógicas.

Hubo un tema en que maestro y discípulo no llegaron a un acuerdo: los tiempos de las alfabetizaciones. Tal vez Bolívar imaginó que, en este estado de guerra y de miseria, era necesario recurrir a métodos pedagógicos que fueran eficientes. Tal vez, siempre sean conflictivas las relaciones entre revolución y pedagogía. En medio de este contexto, Rodríguez y Bolívar no compartían la misma visión sobre el método lancasteriano.

El método lancasteriano consistía en una mera instrucción, no invitaba a leer y problematizar el mundo, los mundos. Nos gusta pensar que leer es problematizar, leer es pensar.

(...) reducir a pocos artículos, las materias- encerrarlas en cuadernillos de pocas hojas para que cuesten poco que pensar para responder; y salgan con lucimiento, a costa poco trabajo todo POCO (Estos cuadernillos se llaman CATECISMOS, y los hay sobre diversas materias, otro librito llamado compendio de todas las ciencias o enciclopedia de los niños, excelente cosa para abreviar (...) Establecer, en las capitales, las ESCUELAS DE VAPOR inventadas por Lancaster, a imitación de las SOPAS A LA RUMPORT establecidas en los hospicios. Con pocos maestros y algunos principios vagos, se instruyen muchachos a millares, casi de balde y salen sabiendo mucho, así como con algunas mermitas de Papin y algunos huesos, engordan millares de pobres, sin comer carne (Rodríguez, Tomo II, 1988. p. 187). 
A veces, lo urgente se termina imponiendo sobre la necesidad. Y, por ello, educar "pueblos que se erijan en naciones" (Rodríguez, Tomo II, 1988, p. 108), es una tarea que demanda mucho tiempo. "Bolívar, que había conocido a Lancaster en Londres, en la casa del Precursor Miranda -interesado también en aquél problema vital para la América Hispana- concibió desde entonces grandes esperanzas en la aplicación de su sistema" (Mijares, 1976, p.XIII). Sin embargo, es necesario afirmar que no sólo Bolívar se ilusionó con Lancaster.

Bajo los auspicios liberales del General San Martín y el cuidado científico del doctor Guillies, Mendoza es un ejemplo de progreso para las otras ciudades sudamericanas. Se estableció una escuela de Lancaster, cuando yo estaba allí -recuerda el inglés Roberto Proctor- y se abrió una biblioteca pública y por añadidura, se editaba un periódico por algunos jóvenes del lugar, que era canal para difundir los principios liberales en todo el continente. Las utilidades se destinaban para costear la escuela, a la que estaba anexo un teatro rústico, donde los mismos jóvenes, a veces representaban (Galasso, 2000, p.115).

Artigas, también propone traer al Río de la Plata el método lancasteriano.

\begin{abstract}
Así, hacia 1821, Larrañaga funda La Escuela Lancasteriana. Para ello, se pone en contacto con Diego Thompson, difusor del sistema lancasteriano en esta parte de América. El nuevo método permitía instruir simultáneamente a un millar de niños con el empleo de un solo maestro, ayudado por los estudiantes más aventajados que eran denominados monitores. Además de contar con la presencia de campanillas y silbatos que asemejaban el aula a un cuartel, este clima militar también estaba acompañado por la rígida disciplina. Lancaster era cuáquero, hijo de obreros. Y se desempeñaba como maestro en un mísero barrio londinense. Debido a los escasos recursos con los que contaba, decidió volver a la vieja enseñanza mutua. Robert Owen llegó a adoptar dicho método en su escuela de New Lanark. Incluso Andrés Bello "opinaba que las ideas de Lancaster eran adaptables en cierta medida a la educación primaria pero las rechazaba para la educación media y la superior (Mijares, 1976, p. XIII).
\end{abstract}

¿Por qué es importante la metáfora Lancaster? Porque nos hace pensar en los sentidos de leer, aprender y educar. Los sentidos de las formaciones docentes: "Piense la Dirección de Estudios en formar maestros antes de abrir Escuelas (...) Tantos millares de niños frecuentan tantos centenares de escuelas (dicen los mensajes). Así están las Escuelas i así saldrán los niños de ellas" (Rodríguez, Tomo I, 1988, p.243).

Lo anterior nos conduce a pensar los vínculos entre alfabetizaciones y democracias, a problematizar las relaciones entre políticas, políticas (socio)educativas y gramáticas pedagógicas.

Conocemos dos maneras de relacionarnos, de vincularnos al mismo tiempo con los saberes en las aulas, en el sentido más amplio de la palabra aula, y por medio de las políticas (socio)educativas. En las aulas y por medio de las políticas podemos rozar biografías.

Esto es, las políticas educativas que no contemplan y comprenden a (las) aulas se demoran, no impactan de la forma que pretenden, y tal vez este demorarse sea un desmoronarse. Si las aulas no cuentan con (las) políticas, pueden quedar enclaustradas. Es por esto que nos convidamos a leer las políticas educativas desde las gramáticas pedagógicas, para que las políticas y las aulas encuentren su articulación en la formación de sujetos producto de pedagogías humanizadoras.

En el siglo XIX se desarrolla el derecho y el deseo a los libros, a las lecturas. Los libros construyen lectoras/ es, y se configuran pedagogías de las lecturas. Llenar las bibliotecas de las escuelas de lecturas nos convoca a poblar las escuelas de imaginaciones. También a imaginar otras escuelas.

En el siglo XXI el derecho y el deseo a las orquestas, a las netbooks. Las netbooks que conectaban igualdades ${ }^{1}$, conectaban también deseos. Deseos en formas de un plan, el plan que deseaba que todas las niñas y los niños tuvieran su Conectar Igualdad. Las netbooks para aprender, enseñar, jugar, mirar, aprender a buscar y buscar para seguir aprendiendo.

Las netbooks y las máquinas de coser. Recuerdos de otros peronismos ${ }^{2}$, recuerdos de estos recientes años. Peronismos recientes. Los viejos peronismos y los peronismos recientes tienen puntos en común, amorosidades en común. Las técnicas de las amorosidades que se pueden leer en una metáfora con las máquinas de coser de Evita y las de conectar igualdad de estos últimos años. Estos años son, parafraseando al viejo Goethe ${ }^{3}$, nuestros años de aprendizaje. Una pregunta nos inquieta ¿Se pueden quitar de los corazones 
las memorias de las netbooks? Los procesos de construcción de las memorias colectivas desbordan los chips, afectan a la conformación del sujeto social superando la continuidad o no de las políticas.

¿Cuánto tiempo lleva construir "un estado educador”? ¿Cuánto tiempo estados educadores plurinacionales? En Argentina, ¿quién narró las historias de los derechos y los deseos durante las últimas gestiones de gobierno ${ }^{4}$ ? Podemos pensar las formas en que, en esta historia tan reciente, se constituyeron tiempos de amorosidades pedagógicas. El programa Nuestra Escuela ${ }^{5}$ puede ser un ejemplo de ello, una acción de gestión política que permitió articular formaciones frente a un ministerio sin escuelas ${ }^{6}$. ¿ No era acaso necesario que un/a maestro/a, pudiera estar formado/a para narrar los derechos como conquista y, por lo tanto, plausible de ser perdidos? Contar las historias latinoamericanas en clave de derechos, narrar las pedagogías del Sur en clave de deseos.

Formar también a las conducciones de las escuelas para no continuar igual que en el siglo XIX. A veces parece como si el tiempo no pasara. Como si los temas del siglo XIX insistieran en quedarse y repetirse. En demorarse como quien está encerrado/a. Los dilemas del siglo XIX parecen ser nuestros dilemas. ¿Puede ser que la conducción de escuelas, colegios, profesorados, universidades no sean libertarias e irreverentes?

Se impone escribir en tiempos de paros docentes, de tomas estudiantiles que reclaman por el sostenimiento y revalorización de la educación pública, escribir pedagogías de las ternuras. No callar, no acallar. La formación docente, la práctica docente, el trabajo pedagógico está amenazado por el neoliberalismo y el neocolonialismo.

\section{SIMÓN Y LAS PEDAGOGÍAS LATINOAMERICANAS}

Las conquistas intentaron silenciar nuestros mitos y nos impusieron las gramáticas raciales y racistas del eurocentrismo. Con la conquista se impuso una manera de pensar dicotómica y binaria; una disección entre el pensar y el sentir; una zanja entre la civilización y la barbarie; una herida al interior de la raza humana, herida jerárquica que afirma que existen razas superiores e inferiores.

Enfrentado a la pedagogía de la crueldad que sostenía que los pueblos originarios, los criollos, las criollas, las cholas y los cholos no eran del todo humanos -es decir, que no estaban siendo-, Rodríguez colocó una pregunta en el corazón de las pedagogías latinoamericanas: ¿qué voz puede pronunciar "no existo"?

¿Cómo nombrar a las colonizaciones? Las colonizaciones económicas se llaman expoliaciones y el maestro de Bolívar intuye que no producir lo nuestro va a generar todo tipo de importaciones:

\footnotetext{
En breve se verán paquetitos dorados, con las armas de la corona, CONTENIENDO greda preparada por un nuevo proceder, para los muchachos acostumbrados a comer tierra. Ya nuestros Sastres se ocupan en echar parches i remiendos, i nuestras costureras en pedir limosna, porque nadie manda hacer vestidos ni camisas -cada día llega una remesa de ropa hecha, i hasta de gorras para los Indios. No faltarán (tal vez) especuladores que piensen en establecer, en Londres o en París, fábricas de Chicharrones, tamales i maíz cocido, para desbancar el comercio de las negras (Rodríguez, Tomo I, 1988, p. 347).
}

El Viejo Mundo - el lugar de origen de los maestros que llegan a América y, por ende, de los "catecismistos", la Enciclopedia y la colonización pedagógica-, corresponde al escenario de Los Miserables, la obra de Víctor Hugo. Constituye un ámbito que está cubierto por un velo brillante que, al ser arrollado, deja ver "el horroroso cuadro de su miseria y de sus vicios - resaltando en un fondo de ignorancia" (Rodríguez, Tomo II, 1988, p.397). Y exhibe un espectáculo tan dantesco que Rodríguez, un observador del mismo, demanda con indignación:

(...) cuéntense los ESCLAVOS en Rusia, en Polonia y en Turquía... agréguense los millones de JUDIOS, que el desprecio mantiene en la abyección — los millones de CAMPESINOS, de MARINEROS y de ARTESANOS... ábranse las puertas de las CARCELES y las de los HOSPICIOS... júntense los SIRVIENTES públicos y domésticos... visítense las casas de JUEGO!! y los LUPANARES!!!... penétrese en los MERCADOS y en los vastos TALLERES de la industria (Rodríguez, Tomo II, 1988, p.397). 
Expoliciones económicas: “(...) la codicia: en el venidero dominará la del verdadero mérito, que es el saber. Entonces se pensará en la sociedad; entonces la conducta social valdrá lo que antes valían las ejecutorias y lo que ahora valen las talegas" (Rodríguez, Tomo I, 1988, p. 348).

Simón diferencia dos clases de necesidades: las indispensables y las ficticias o facticias. Las primeras, con un sesgo rousseauaniano, pueden ser consideradas como naturales (alimento, vestido, alojamiento, curación y distracción). Y las segundas, por el contrario, pueden ser tenidas como no naturales o artificiales. "Los hombres se juntan y entreayudan pero... entreayudarse para adquirir cosas, no es Fin social" (Rodríguez, Tomo I, 1988, p. 228). La entreayuda para adquirir cosas es el cada uno para sí mismo:

Industria! Comercio! Banco! Crédito público! en boca de unos pueblos que apenas empiezan a salir del cascarón... ¿ ¿no será Presunción? Cuidado! En el sistema antieconómico (llámese SISTEMA, si se quiere) de concurrencia o de oposición, el productor es víctima del consumidor, y ambos lo vienen a ser del capitalista especulador (...) En la producción superflua está la desgracia del hombre: por ella pierde y se empobrece: la pobreza lo somete a condiciones duras, y, al fin, la miseria lo vende al capitalista (Rodríguez, Tomo I, 1988: 240).

Aquí, la industria aparece con claridad como la contracara del artesanado.

Que la división de trabajos, en la confección de las obras, embrutece a los obreros, y que, si por tener tijeras superfinas y baratas hemos de reducir al estado de máquinas a los que las hacen, más valdría cortarnos las uñas con los dientes: por el contrario, Que la división de trabajos en la producción es necesaria: porque la superabundancia de una misma cosa en todo en un país, abarata el producto, desprecia el trabajo y empobrece al productor (Rodríguez, Tomo II, 1988, p. 13).

Las necesidades de los hombres de la república exigen el empleo de medios nuevos: “(...) debemos emplear medios... TAN NUEVOS! como es NUEVA! la Idéa de VER por el BIEN de TODOS” (Rodríguez, Tomo II, 1988, p. 34).

Aparece también la idea de colonizaciones culturales. Rodríguez cree que es un disparate traer "Ideas Coloniales a las Colonias! (...) ¿Estamos tratando de quemar las que tenemos?” (Rodríguez, Tomo I, 1988: 345). ¿Colonización para qué? "Para enseñarnos a regatear, correr, pujar, renegar en varias lenguas y emborracharnos a la Europea” (Rodríguez, Tomo I, 1988, p. 346).

Rodríguez propuso tomar críticamente la lengua del dominador para que junto a otras lenguas nos permitieran nombrar(nos). Un hombre y una mujer capaz de pronunciar, de pronunciarse, de "asaltar", saltar y tomar la palabra. La palabra y la dicha. La palabra dicha. Hombres y mujeres capaces de pronunciar el mundo, de construir mundos con las manos y las palabras; no repetir o imitar mundos.

Tal vez en el siglo XXI sea necesario complejizar aún más las lecturas sobre las colonialidades y preguntarse: ¿Cuánta igualdad "soporta” una sociedad? Cabe reflexionar sobre las (de)formaciones liberales y el individualismo. También reparar sobre el odio como base, como fundamento de las colonialidades. Los odios están sueltos. Las memorias y los odios, las memorias de los odios.

Las conquistas y las pedagogías de la crueldad: yo conquisto. Entonces, ¿yo conozco? ¿Qué es conocer? ¿Cuáles son los vínculos entre el conocer y el ser? Los conocimientos se comparten o no son conocimientos. ¿Qué pedagogías pueden construir los saberes compartimentados, los saberes en compartimentos estancos?

Las pedagogías pueden ser gramáticas para desarmar los odios y forjar otras formas de pensar, sentir la vida con otras/os, la vida en común, es decir estar siendo en comunidades. Pedagogías necesarias en un Estado gerencial, contrario al Estado de bienestar.

Frente a un pensamiento binario y dicotómico, Rodríguez pensaba, escribía y soñaba desde el Sur. Mirar desde el continente y las islas presume una mirada compleja, mestiza. Por ello, en Rodríguez aparece un pensamiento relacional. Formar ciudadanos y pueblos. Pensar desde el Sur hacia la humanidad. Vincular las pedagogías con el trabajo, construyendo una autonomía no declamada sino productiva. Un pensar desde las igualdades y las diferencias, un pensar diverso. No existe el puro pensar ni el pensar puro. Tal vez, Rodríguez siga construyendo el sueño futurista de un Estado plurinacional. Una pedagogía generadora que crea y cree en las potencialidades de los pueblos de la América del Sur. 
En los pueblos de Nuestra América también creía José Martí, quien observaba que las y los campesinas/os no podían dejar sus trabajos para ir a la ciudad a estudiar.

¡Pues nada menos proponemos que la religión nueva y los sacerdotes nuevos! ¡Nada menos vamos pintando que las misiones con que comenzará a esparcir pronto su religión la época Nueva! (...) El mundo está de cambio (...) Andamos sobre las olas, y rebotamos y rodamos con ellas; por lo que no vemos, ni aturdidos del golpe nos detenemos a examinar, las fuerzas que la mueven. Pero cuando se serene este mar, puede asegurarse que las estrellas quedarán más cerca de la tierra (Martí, 1991, p. 100).

Martí está proponiendo misiones pedagógicas: "En suma se necesita abrir una campaña de ternura y de ciencia, y crear para ella un cuerpo, que no existe, de maestros misioneros" (Martí, 1991, p. 102). Los maestros misioneros serían maestros ambulantes que recorrerían los pueblos alfabetizando.

La revolución cubana de 1959 hizo suyas las palabras del apóstol y emprendió las primeras misiones con maestras/os, estudiantes de profesorados y jóvenes. La bandera del territorio, libre de analfabetismo, comenzó a agitarse amorosamente en 1961.

Durante el gobierno de Cámpora, en el año 1973, en Argentina se inició la Campaña de Reactivación

Educativa de Adultos para la Reconstrucción $(\text { CREAR })^{7}$. Las palabras yerba mate -como expresión compuesta- se constituyeron en las principales palabras generadoras; el mate es la infusión más tradicional y para problematizar la producción, se la asoció a la yerba ${ }^{8}$. Una palabra generadora y generosa para aprender a leer, para compartir y convidarnos con la lectura.

En la actualidad, en la República Bolivariana de Venezuela, se llevan adelante las misiones pedagógicas. La misión Robinson (por Samuel Robinson, nombre de Simón Rodríguez luego de escapar de Venezuela), es un programa social para terminar con el analfabetismo. También hoy la Revolución Bolivariana ha comenzado a agitar con ternura la bandera del territorio libre del analfabetismo.

Las alfabetizaciones latinoamericanas vienen a poblar de palabras los silencios de las conquistas. ¿Es posible ser expulsado de una lengua sin ser expulsado de la existencia? ¿Se puede deshabitar una lengua? Compartir nuestros relatos y convidarnos con las palabras que hablan de nosotras/os, de las historias latinoamericanas, de las pedagogías latinoamericanas para no ser habladas/os por una gramática colonial y racial.

De la mezcla de las imposiciones y de las apropiaciones surgen nuestras palabras. Se trata de formar hombres y mujeres que puedan nombrar y nombrarse en sus mundos, en estos mundos complejos, mestizos. Las pedagogías latinoamericanas están siendo una narrativa donde encontrarnos y descubrirnos.

Nos gusta imaginar a Rodríguez rodeado de libros, dialogando con ellos. "Leer es resucitar ideas y para hacer esta especie de milagro es menester conocer los Espíritus de las difuntas o tener espíritus equivalentes que subrogarles" (Rodríguez, Tomo II, 1988, p. 215).

Leer a Rodríguez hoy, resucitar sus ideas y hacer un milagro cuando los milagros están encerrados. Milagros encerrados, demorados. Simón y Milagro. Los milagros de Simón. Lo imaginamos también esperando, esperándonos con sus dignidades, con sus ternuras.

Si la Instrucción se proporcionara a TODOS ¡¿cuántos de los que nos obligan a echar cerrojos a nuestras puertas, no serían Depositarios de las llaves?! ...i¿Cuántos de los que tememos en los caminos, no serían nuestros compañeros de viaje?! (...) que las mas de las mujeres, que excluimos de nuestras reuniones por su mala conducta, las honrarían con su asistencia; en fin, que, entre los que vemos con desdén, hai muchisimos que serían mejores que nosotros, si hubieran tenido Escuela (Rodríguez, 1988, T.I, p. 327).

Nos gusta leer a Rodríguez, dialogar con él, con su contemporaneidad.

Yo no he venido a la América porque nací en ella, sino porque tratan sus habitantes ahora de una cosa que me agrada, i me agrada porque es buena, porque el lugar es propio para las conferencias y los ensayos (Rodríguez, Tomo II, 1988, p. 504).

Ensayo en el doble sentido de la palabra, como escritura y como posibilidad de ensayar una nueva pedagogía, una nueva gramática y una nueva política. Ensayos de gramáticas y políticas. Ensayos pedagógicos. 
Los tiempos de las Repúblicas son "el crepúsculo de las Luces Sociales que empieza a rayar" (Rodríguez, Tomo II, 1988, p. 360). Entonces ni en tiempos de guerras, ni en tiempos neoliberales y coloniales hay que ahorrar palabras, ideas, papeles.

Rodríguez hace la distinción entre Independencia y Libertad: “(...) la Independencia no se disputó con plumas = un Código no se discute a balazos” (Rodríguez, Tomo I, 1988, p. 381). Si la concreción de la independencia exige la guerra contra los españoles, la obtención de la libertad requiere el empleo de la pluma y, por lo tanto, el ejercicio de la educación.

La guerra de la Independencia fue contra los soldados de un rei, armados por las preocupaciones - La de la LIBERTAD debe ser contra las preocupaciones para que no vuelvan a armar otros brazos. Con la espada se cortan NUDOS inextricables no PLUMAS (Rodríguez, Tomo II 1988, p. 383).

La pluma es liviana y al mismo tiempo escribe, convence y puede vencer. La pluma dibuja murales que no son muros desde los tiempos inmemoriales.

Los deseos de comunicar(nos), de dejar huellas. Deseos y necesidades de producir signos, de perdurar en signos. Pintadas y dibujos en cuevas y muros. Las primeras poéticas en una pared, poéticas comunitarias. Las manos y los signos. Las manos únicas y comunitarias.

Las poéticas que fueron encerradas en nombre de la propiedad privada. La privada propiedad. Otros muros. Esta vez, con vallas, rejas. Muros vigilados, historias y memorias vigiladas, uniformadas. Lo uniforme frente a lo que la vida desborda. Las poéticas pintadas se escapan, se expanden en los murales, en los muralismos del sur ${ }^{9}$, dando cuenta de las memorias, luchas y legados colectivos, formando parte de una cultura común, de todos. Historias pintadas, memorias dibujadas. Bocetos de libertades y tierras. Telas y telares. Gramáticas textuales y textiles. Entre libros y alpargatas.

¿Los sures tienen dueños? ¿Y los suelos? Pensar a contrapelo de los dueños. Pensar a pesar de los dueños del suelo. Los dueños en los tiempos de Rodríguez, los propietarios hoy. De lo que no son dueños, es de los tiempos. A pesar de los temporales, los tiempos son de los pueblos. Los tiempos son nuestros. Los tiempos se conjuran y conjugan en pasados, presentes y futuros. Las manos nos prometen otros tiempos. Decimos junto a nuestro contemporáneo Rodríguez "el tiempo es el lugar de la acción” (Rodríguez, Tomo II, 1988, p. 360). El tiempo es un lugar, un espacio. El sur es un espacio y un tiempo esperanzador. Ser desde el sur, ser/sur. Los deseos de ser y del ser. Los deseos del sur.

\section{Bibliografía}

Aristóteles (2002). Etica Nicomáquea. Buenos Aires: Alianza Editorial.

Bolívar, S. (1990). Escritos Políticos.Madrid: Alianza.

De Sousa Santos, B. (2009). Epistemología del Sur. Buenos Aires: Siglo XXI. CLACSO.

Galasso, N. (2000). Seamos Libres y lo demás no importa nada. Buenos Aires: Colihue.

Martí, J. (1991). Obras Completas. La Habana: Editorial Ciencias Sociales.

Mijares, A. (1976). Simón Bolivar, Doctrina del Libertador. Venezuela: Biblioteca Ayacucho.

Rodríguez, S. (1988). Obras Completas. Caracas: Ediciones del Congreso de la República de Venezuela.

Rodríguez, S. (2015). Sociedades americanas. Buenos Aires: Urbanita

Roig, A. (2009). Teoría y critica del pensamiento latinoamericano. Buenos Aires: Una Ventana.

Rozitchner, L. (2012). Filosofía y emancipación. Simón Rodríguez: el triunfo de un fracaso ejemplar. Buenos Aires: Biblioteca Nacional. 


\section{Notas}

1 Programa lanzado en el año 2010 por el gobierno argentino con el fin de reducir las brechas digitales, educativas y sociales. Pautó la entrega de millones de computadoras y la apertura de aulas digitales en todo el país.

2 Movimiento político surgido en Argentina a mediados de la década de 1940 alrededor de la figura de Juan Domingo Perón, presidente de la República en los periodos 1946-1951, 1951-1955 (es derrocado por un golpe de estado) y 1973-1974, año en que fallece. Durante su primera presidencia se desarrolla fuertemente el Estado de Bienestar, se fortalece el sindicalismo y se despliegan políticas sociales. En esto último, la figura de Eva Perón y su Fundación adquieren relevancia aportando con la construcción de escuelas, hospitales, hogares para niños, ancianos, madres solteras, y distribuyendo libros, alimentos, juguetes y máquinas de coser.

3 Pensador alemán (1749-1832) muy influyente en el Romanticismo. Nos referimos a su obra "Los años de aprendizaje de Wilhelm Meister", publicada por primera vez en 1975-76, segunda novela del autor. La misma aborda a través de sus personajes el camino de la formación o la auto-formación.

4 Nos referimos a las presidencias de Néstor Kirchner (2003-2007) y Cristina Fernández de Kirchner (2007-2011; 2011-2015)

5 El programa Nuestra Escuela comienza a implementarse en el año 2013, es un Programa Nacional de Formación Permanente para educadores en ejercicio, con características de gratuidad y universalidad, esto es, de alcance nacional. Se enmarca en la Ley de Educación Nacional (26.206), retomando la concepción de la educación como derecho y del conocimiento como bien público.

6 La Ley Federal de Educación (24.195), sancionada en 1993, desarrolla y profundiza la transferencia de las escuelas a las provincias, quedando el Ministerio de Educación de la Nación sin escuelas que dependan de él directamente en términos de financiamiento y de gestión curricular.

7 Dicha campaña tuvo como objetivo la alfabetización de adultos, se formula tomando como punto de partida la propuesta de alfabetización de Paulo Freire, articulada con el pensamiento nacional y popular, desde el cual se consideraba a la educación de adultos como uno de los elementos principales para la construcción de la nación, partiendo de la formación de la conciencia de los sectores más populares de la sociedad. A los pocos meses de lanzada la campaña asume el gobierno Juan Domingo Perón, quien la continúa, pero al fallecer este (1974) pierde fuerza y se termina disolviendo.

8 El mate como infusión se prepara a partir del cultivo y producción de la planta de la yerba mate. Es una infusión característica de Argentina, Uruguay, Paraguay y parte de Brasil.

9 Movimiento pictórico que va desde México hasta nuestro país y que plasma memorias de los pueblos originarios, de los trabajadores y oprimidos, sus luchas, sus culturas, sus reivindicaciones. 